\title{
Human Mars EDL Pathfinder Study: Assessment of Technology Development Gaps and Mitigations
}

\author{
Randolph Lillard \\ NASA Johnson Space Center \\ 2101 E NASA Parkway \\ Houston, TX 77058 \\ 281-483-4629 \\ randy.lillard-1@ nasa.gov \\ Alicia Dwyer Cianciolo \\ NASALangley Research Center \\ Hampton, VA 23681 \\ 757-864-8620 \\ Alicia.m.dwyercianciolo@nasa.gov
}

\author{
Joe Olejniczak \\ NASA Ames Research Center \\ Moffett Field, CA 94035 \\ 650-604-3252 \\ joseph.olejniczak@nasa.gov
}

\author{
Michelle Munk \\ NASA Langley Research Center \\ Hampton, VA 23681 \\ 757-864-2314 \\ michelle.m.munk@nasa.gov
}

Bret Drake

The Aerospace Corporation

2525 Bay Area Blvd.

Houston, TX 77058

281-283-6440

bret.g.drake@aero.org

\author{
Tara Polsgrove \\ NASA Marshall Space Flight \\ Center \\ Huntsville, AL 35811 \\ 256-544-1274 \\ tara.polsgrove@nasa.gov \\ Charles Whetsel \\ Jet Propulsion Laboratory \\ 4800 Oak Grove Dr. \\ Pasadena, CA 91109 \\ 818-359-1400
}

Charles.w.whetsel@jpl.nasa.gov

\begin{abstract}
This paper presents the results of a NASA initiated Agency-wide assessment to better characterize the risks and potential mitigation approaches associated with landing human class Entry, Descent, and Landing (EDL) systems on Mars. Due to the criticality and long-lead nature of advancing EDL techniques, it is necessary to determine an appropriate strategy to improve the capability to land large payloads. A key focus of this study was to understand the key EDL risks and with a focus on determining what "must" be tested at Mars. This process identified the various risks and potential risk mitigation strategies along with the key near term technology development efforts required and in what environment those technology demonstrations were best suited. The study identified key risks along with advantages to each entry technology. In addition, it was identified that provided the EDL concept of operations (con ops) minimized large scale transition events, there was no technology requirement for a Mars pre-cursor demonstration. Instead, NASA should take a direct path to a human-scale lander.
\end{abstract}

\section{TABLE OF ConTENTS}

1. INTRODUCTION 1

2. ENTRY SYSTEMS CONSIDERED .. 2

3. ENTRY SYSTEM RISK ASSESSMENT ......................... 4

4. FORWARD WORK .............................................. 6

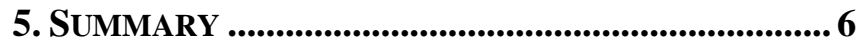

ACKNOWLEDGEMENTS ............................................6 6

REFERENCES..........................................................6

BIOGRAPHY ............................................................ 7

U.S. Government work not protected by U.S. copyright

\section{INTRODUCTION}

NASA is developing a long-term strategy for achieving extended human missions to Mars in support of the policies outlined in the 2010 NASA Authorization Act and National Space Policy. The Authorization Act states "A long term objective for human exploration of space should be the eventual international exploration of Mars." Echoing this is the National Space Policy, which directs that NASA should, "By 2025, begin crewed missions beyond the moon, including sending humans to an asteroid. By the mid-2030s, send humans to orbit Mars and return them safely to Earth." Further defining this goal, NASA's 2014 Strategic Plan identifies that "Our long-term goal is to send humans to Mars. Over the next two decades, we will develop and demonstrate the technologies and capabilities needed to send humans to explore the red planet and safely return them to Earth." Over the past several decades numerous assessments regarding human exploration of Mars have indicated that landing humans on the surface of Mars remains one of the key critical challenges. In fact, the general opinion previous to this study was that a sub-scale end-to-end demonstration at Mars of the EDL system was a requirement of the verification and validation plan.

To enable a human campaign to Mars that assumes an extended presence on the surface, on the order of 100 metric tons of usable payload is required. This includes, but is not limited to a habitat, rover, ascent vehicle (for a return trip to Earth), power system, and other modules. Previous assessments [1] have shown that an optimal approach to 
landing over 100 metric tons of payload on Mars is to break the total landed mass into smaller amounts where a single landing would provide the minimum mass possible while packaging the largest vehicle. This study was directed to use 20 metric tons as the usable payload mass and utilize aerocapture into Mars orbit. In addition, the entry systems were directed to fit within the SLS 10m shroud.

20 metric tons of usable payload mass is a 20x increase over the usable payload delivered by the Mars Science Laboratory (MSL) vehicle, which successfully landed on the order of 1 metric ton of usable payload to the surface. MSL relied on Viking heritage decelerator technologies, a disk gab band parachute and a 70 deg sphere cone rigid capsule along with the sky crane technique, which utilized retro propulsion to complete the descent and landing sequence. Previous analysis by Braun [1] and Steinfeldt [3] has shown that these tradition Mars landing systems that utilize parachutes have a performance limit on the order of $2 \mathrm{mt}$. Based on this performance limit, new entry descent and landing technologies and techniques are required to land substantially larger payloads at Mars.

\section{ENTRy SySTEMS CONSIDERED}

Previous NASA studies [4] have shown there are multiple EDL scenarios and technologies that can potentially deliver these large payloads. This study highlights four of the most likely concepts and assessed the development plans for each with a focus on major risks. An overview of these can be found in Cianciolo and Polsgrove [5]. The EDL systems classified are done so in terms of their Ballistic number $(\beta)$, which is the ratio of Mass to drag coefficient multiplied by cross sectional area. Two entry concepts are presented for each $\beta$ classification. All four of the concepts utilize supersonic retro-propulsion (SRP) for descent and are design to provide precision landing.

\section{Low Ballistic Number Vehicles}

These EDL systems characteristically have $\mathrm{b}$ between 150 200. These systems have rigid, blunt centerbodies that have deployable or inflatable heatshield extensions that significantly increase the drag area without a significant mass increase. The two leading concepts are the Hypersonic Inflatable Aerodynamic Device (HIAD) and the Adaptable, Delivery Entry Placement Technology (ADEPT). L/D ratios are generally less than 0.2 for these configurations. Because the heatshield has a large diameter in comparison to the centerbody (diameter ratio on the order of 2:1), the EDL vehicle does not need a backshell to protect the payload, thus reducing mass and providing for more flexible packaging options.

\section{$H I A D$}

This concept, pictured in figure 1, is an inflatable system that is stowed until shortly before entry at Mars begins, at which point the system inflates using gas generators to inflate the heatshield. The outer layer of the system utilizes a flexible thermal protection system, which is constructed of ceramic outer fabric with customizable layers of flexible insulation (such as carbon felt or Aerogel felt). Inflatable structure utilizes braided fiber and fluoropolymer liner toroids stacked with pairing and radial straps

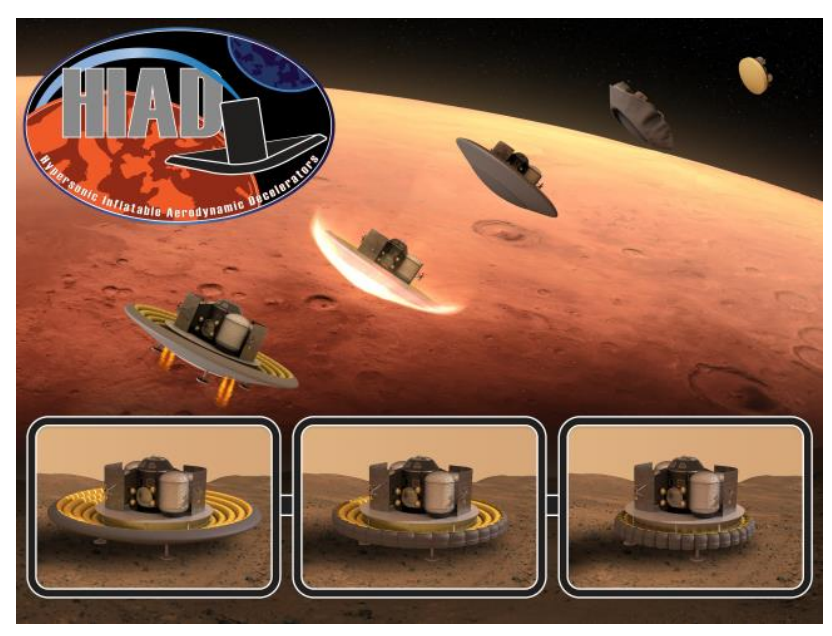

Figure 1. HIAD concept of operations.

Figure 1 also shows the concept of operations for the HIAD system. Although previous assessments have jettisoned the HIAD during the entry sequence, the concept of operations utilized here retains the HIAD for the duration of the descent and landing phases. The rigid centerbody was designed to utilize the same flexible TPS material that makes up the outer layer of the inflated system. The rigid heatshield stores the SRP engines. For this configuration the SRP engines ignite between Mach 2 and 3. For a detailed description, see Polsgrove et al. [6].

\section{ADEPT-}

The ADEPT configuration, pictured in figure 2, is similar to HIAD in shape and function, but instead utilizes a deployable system to create the large increase in vehicle diameter. The flexible carbon cloth is the heatshield extension. The current design utilizes a 3D woven system, although other flexible systems could be utilized. Structural ribs provide the shape and support of the flexible TPS. Figure 2 shows the stowed and deployed configurations while figure 3 details the design of the ribs and their configuration in a deployed state. The flexible TPS is pushed taken from a stowed to deployed configuration with ribs, essentially pushing the heatshield forward, like an umbrella. The key technology enabler for ADEPT is the flexible multi-layer woven carbon fabric that forms a semi-rigid membrane when pre-tensioned by deployment of supporting ribs. This multi-layered woven fabric must transfer aerodynamic loads to the support structure while operating at very high temperatures due to aeroheating. The bottom layers of the cloth carry the aerodynamic load while the top layers manage the thermal energy. A detailed description is given in Cassel et al. [7]. 


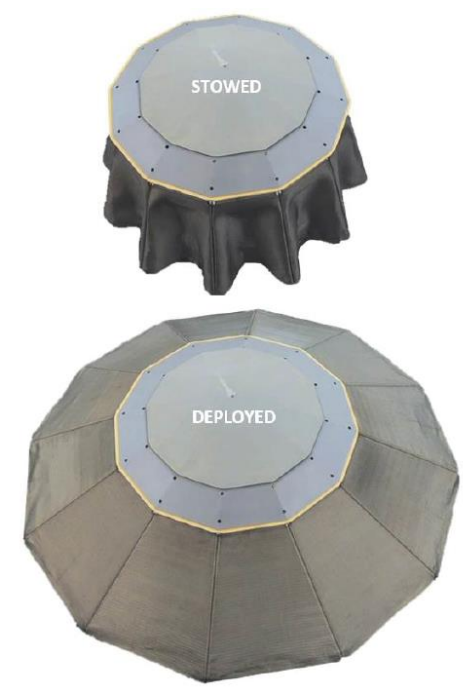

Figure 2. ADEPT vehicle detailing stowed and deployed heatshield configurations.

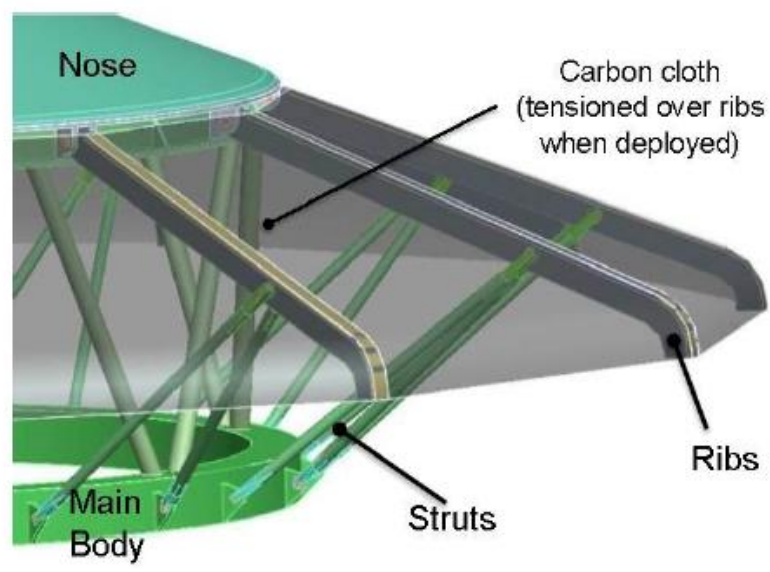

High Ballistic Number Vehicles

Figure 3. ADEPT deployed configuration with strut design.

\section{$M I D L / D$}

The high ballistic number Mid-L/D Rigid Vehicle (MRV) concept initially developed using the COBRA (REF) shape optimization tool. It is a fully rigid entry vehicle concept which minimizes DDT\&E by leveraging proven heritage tools, materials, control, and processes. Figure 4 details the entry configuration and the current plan for SRP nozzle integration. The lander components are integrated in the rigid aeroshell and the aeroshell is retained all the way to landing (concept of operations is shown in figure 5). In most past studies, the Mid L/D aeroshell was shed prior to touchdown. This is a significant difference. By retaining the aeroshell, the transition to a powered retro burn is simplified. The descent engines integrate in the lower sides of the OML. They are ignited at a supersonic condition and complete the supersonic retropropulsion (SRP) burn, safely steering the vehicle to a soft landing. The aeroshell protects the payload from the environment during the entry and landing, as well as aerocapture. The control scheme uses RCS jets for maneuvering, and split body flaps and main engine throttling for trim. A detailed description is given in Cerimele et al. [8].
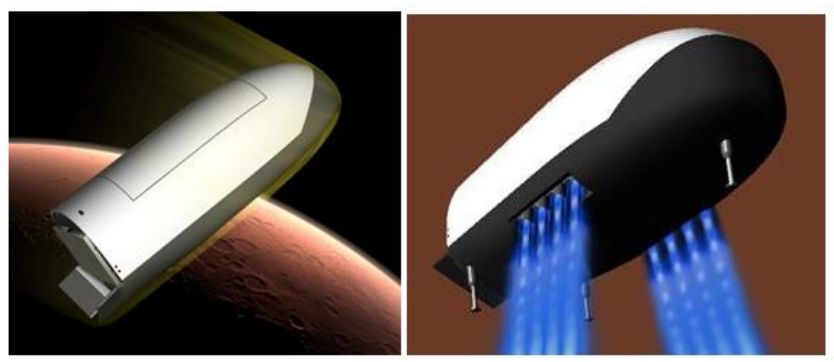

Figure 4. Mid L/D vehicle showing entry configuration and descent configuration with SRP engines firing.

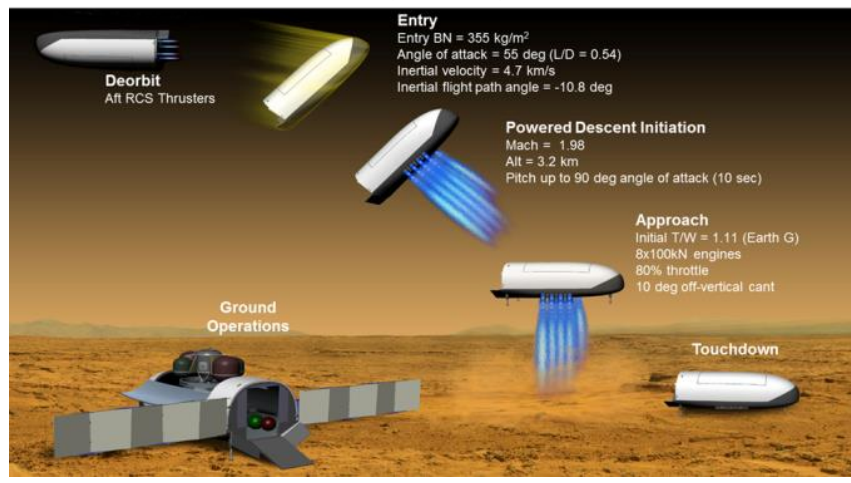

Rigid Capsule-

The concept proposed by Price et al [9] utilized a scaled Mars Science Laboratory shape for the heatshield. Unlike the other

Figure 5. Mid L/D concept of operations.

three concepts, the team formulated this outside of the Evolvable Mars Campaign (EMC) and thus did not strictly conform to the same requirements as the other configurations. The capsule utilized a $10 \mathrm{~m}$ diameter entry vehicle that launched unshrouded, in a slight hammer-head configuration on the SLS. The ogive shaped backsell also serves as the launch fairing on SLS. The concept utilized a non-cryogenic biprop system with multiple pump-fed engiens for descent stage propulsion (other configurations utilized cryogenic loxmethane). In addition, the vehicle included a fully fueled Mars Ascent Vehicle (MAV), which allowed for abort scenarios to be investigated (other configurations landed with a dry MAV). 


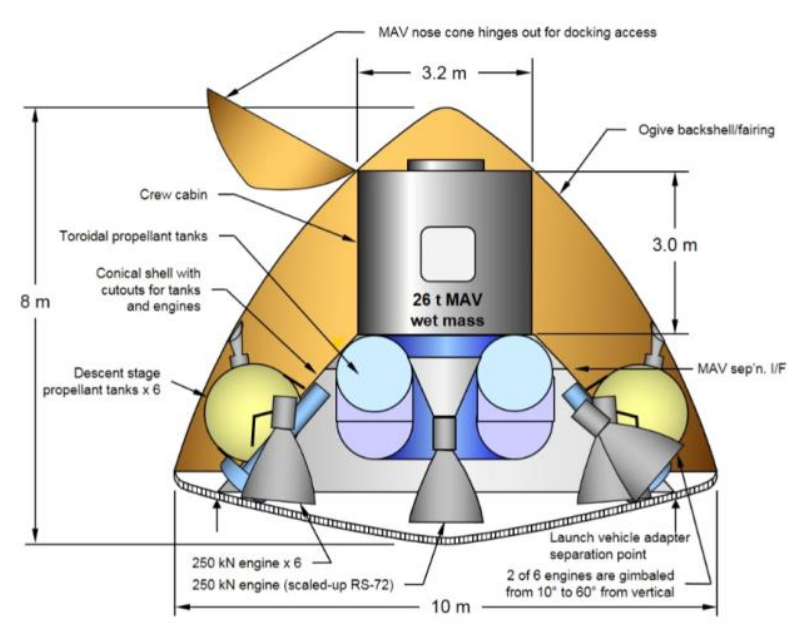

Figure 6. Rigid capsule cross-section with design details.

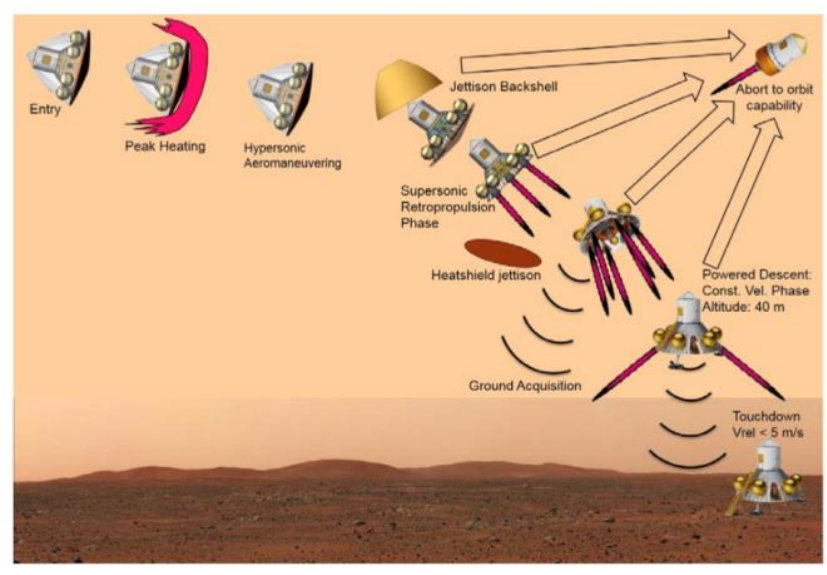

Figure 5. Rigid capsule concept of operations.

\section{ENTRY SYSTEM RISK ASSESSMENT}

This study assessed the risks for the candidate EDL systems by developing detailed mitigation strategies, along with cost estimates and schedules, for each of the concepts. By determining common mitigaton steps among the EDL concepts and developing high level schedules for the required mitigation steps, this process also allows a prioritization of near-term technology development activities and investments, and an assessment of the time criticality of starting such activitites and investments.

Specifically, this study sought to determine the benefits flight demonstration at Mars relative to full-scale Earth flight demonstration, sub-scale Earth flight demonstration, ground testing, high-fidelity numerical simulations, and engineering analysis. Of particular interest was understanding the benefit of Mars demonstration given the high cost and long time frame of any such demonstrations. From the outset, it was clear that it would highly desirable if not misision enabling (from a practical cost and schedule sense) to not require a Mars demonstration and to minimize large scale flight testing at Earth.

A key product of the risk assessment is a cost-benefit analysis resulting in a catalog of mitigation options as a function of cost, schedule, and risk reduction benefit. Such a catalog will allow NASA to make informed decisions about the design and development of the EDL system, allowing not only comparisons among the EDL concepts but also informing risk-leveling across other elements of the architecture. For example, for a given risk tolerance position, the cost and schedule are defined. Likewise, for a given cost, the amount of residual risk is defined.

At the beiginning of the risk assessment, a concept of operations was developed for each EDL concept. The concept of operations included the impacts and consequences of the accomodating the common technologies of SRP and safe precision landing. Essentially, each EDL concept needs to deliver the lander to a Mach-altitude box that will enable the SRP system to operate in conjunction with the safe precision landing system to meet landing requirements.

Early in the study in became obvious the most significant EDL risk was the transition from the entry decerator phase to the descent / propulsion phase. The design of a transition sequence to separate a heavy and rigid lander from a light and high drag entry system has been the subject of much analysis and debate for many years with no evident solution. Such a transition sequence would need to cover a large envelope of speed and altitude, and would be very difficult and expensive to simulate at Earth at relevant scales and conditions.

Thereofore, the team decided to remove the tranistion event from the concept of operations and retain the decelerator system to the ground. This approach does shift risk and complex engineering development to the various subsystems, but it lowers the overall risk of the EDL system. Initial analysis shows a $2-3$ metric ton loss in landing performance.

\section{Major Risks Common to All Concepts}

Four risks, described below, were identified as being common to all Mars EDL scenarios. In terms of these risks, the four EDL concepts have different advantages and disadvantages requiring mitigation plans of varying scope.

\section{Supersonic Retro Propulsion-}

There are a number of challenges associated with developing an integrated SRP system. The integration of the SRP thrusters into the heatshield or rigid centerbody is a significant engineering challenge. Either retratcable doors or a plug jettison concept could be made to work, but further engineering development is needed. The interactions between the aerodynamic forces, flight dynamics, control system, and propulsion system are complex and will require significant analysis, ground testing, and sub-scale flight testing at Earth. Finally, the SRP plume interactions wth the 
ground creates landing hazards such as plume ejecta that can interfere with landing sensors and provide debris to potentially damage the lander.

\section{Vehicle Integrated Performance-}

The controllabillity of the lander is a major concern, especially for low ballistic coefficient vehicles that may lack sufficient aerodynamic control authority to meet landing accuraccy requirements. Additionally, high ballistic coefficient vehicles need to demonstrate robustness to $\mathrm{cg}$ location and location uncertainty.

\section{Propulsion Development-}

Long duration cryofluid management for minimizing propellant loss, highly throttleable LOX/Methane engines, and integrated RCS fed by low pressure main tanks are required for all concepts.

\section{Safe Precision Landing-}

Terrain Relative Navigation (TRN) development and realtime Hazard Detection and Avoidance (HAD) during approach to the landing target to resolve surface features are also required [add ref].

\section{High Ballistic Number Vehicles}

Specific Risks - (**explain bullets after data drop in Nov**)

- New TPS materials and integrating openings in heatshield could require wind tunnel tests and/or flight demonstrations

- Qualification / certification of soft structures (pressure stabilized) is an uncertain process to human spaceflight community (e.g. Centaur upper stage story)

- Need to understand scalability of deployable / inflatable structures

- Aeroelastic effects may require significant tests / modeling campaign to assess

- Controllability schemes will need more analysis (RCS effectiveness due to positioning and/or CG movement and moment of inertia impacts on vehicle movements)

- Controllability will need to be demonstrated if active system is utilized

\section{Advantages-}

- More volume for packaging, especially compared to capsules

- Past studies have indicated that gear ratios (entry mass to payload mass) are more favorable than high ballistic coefficient vehicles

\section{Low Ballistic Number Vehicles}

Specific Risks-(**explain bullets after data drop in Nov**)
- $\quad$ Packaging - determine how gear ratio compares to low b options and how to accommodate multiple payload geometries

- $\quad$ Need to identify the break point for landed mass where high $b$ options are not feasible

- If additional performance is required, technologies can be brought in to improve performance but that will come with development / certification / demonstration costs (wings, aeropropulsion, etc)

- Dual load paths for mid L/D could require increased mass

\section{Advantages-(**explain bullets after data drop in Nov**)}

- Heritage materials and previously flown integration techniques will provide minimal need for aerothermal demonstrations (new OML shapes will need to be assessed for off-nominal performance)

- Qualification and certification well understood

- $\quad$ Moving to smaller shroud (8.4 m) may provide mid L/D packing advantage due to horizontal packing options

Without deployable / inflatable, SRP could utilize exposed engine without thrust vector control, potentially reducing complexity

\section{Major Demonstrations Needed}

Add discussion after nov drop***.

\section{Table 1 . List of demonstrations required with their execution location. operations.}

\begin{tabular}{|l|l|}
\hline \multicolumn{1}{|c|}{ Demonstration / Development } & \multicolumn{1}{c|}{ Execution Location } \\
\hline Cryogenic fluid management zero boil off & LEO \\
\hline LOX/LCH ${ }_{4}$ engine development & Earth ground testing \\
\hline SRP plume / ground interactions & $\begin{array}{l}\text { Earth ground testing and/or Mars } \\
\text { opportunities }\end{array}$ \\
\hline TPS system level demonstration & Earth entry (Mars comparable conditions) \\
\hline Active controllability for entry system & $\begin{array}{l}\text { Earth entry (perhaps sub orbital } \\
\text { conditions) }\end{array}$ \\
\hline $\begin{array}{l}\text { SRP system level controllability (ignition, } \\
\text { stable control, aero/aerothermal, etc.) }\end{array}$ & Sub orbital (high-altitude) Earth conditions \\
\hline
\end{tabular}

\section{EDL Precursor Assessment}

Options available to mitigate risks with on- or near-earth testing were identified such that a sub-scale demonstration mission at Mars dedicated to EDL risk reduction and data collection is not, in the opinion of the participants, justified as a mandatory part of the lander development program (assumes retention of the entry system). However, in the context of ongoing agency objectives requiring access to the surface of Mars, evolving the architecture of future robotic Mars landers to incorporate design strategies that would inform and educate the later design of human-scale vehicles, is endorsed by this group as an effective risk reduction strategy as an element of NASA's agency-wide priorities for Mars exploration. 


\section{FORWARD WORK}

**Awaiting external peer review findings (chaired by Bobby Braun) and NASA response. Review is complete and report was delivered Week of Oct $17^{\text {th }}$, so this section will be complete within November.**

\section{SUMMARY}

This study presented an assessment of the major development risks associated with developing a human scale architecture to sustain a human presence on Mars. The vehicle concepts were classified as either low or high ballistic number and the risks and major demonstrations needed to mitigate these risks were discussed. The study identified there are several common risks to all architectures that can be mitigated for all configurations. In particular, SRP is an enabling technology that will be utilized by all configurations. In addition, the study identified a concept of operations for each concept that places the major risk in flight regimes where they can be demonstrated and mitigated in the Earth or near Earth environment. This removes the need for an end to end demonstration at Mars of the EDL system. This approach allows for a segmented Verification and Validation approach instead of relying on one major demonstration.

\section{ACKNOWLEDGEMENTS}

The authors would like to thank the entire NASA and JPL team that supported this activity.

\section{REFERENCES}

[1] Craig, Douglas A., Herrmann, Nicole B., and Troutman, Patrick A. "The Evolvable Mars Campaign - Study Status," IEEE Aerospace Conference, Big Sky, MT, March 7-14, 2015.

[2] Braun, R.D., Manning, R.M., "Mars Exploration Entry, Descent and Landing Challenges," Journal of Spacecraft and Rockets, Vol. 44, No. 2, pp. 310-323, 2007.

[3] Steinfeldt, B.A.; Theisinger, J.T.; Korzun, A.M.; Clark, I.G.; and Braun, R.D.; "High Mass Mars Entry, Descent and Landing Architecture Assessment," AIAA 2009-6684, 2009 AIAA Space Conference, September 2009

[4] EDL-SA reference

[5] Cianciolo, A. D., Polsgrove, T. T. "Human Mars Entry, Descent, and Landing Architecture Study Overview" SPACE 2016, AIAA 2016-5494

[6] Polsgrove, Tara P., Chapman, J., Sutherlin, S., Taylor, B., Fabisinski, L., Collins, T., Cianciolo, A., Samareh J., Robertson, E., Studak, W., Vitalpur, S., Lee, A., Rakow, G. "Human Mars Lander Design for NASA's Evolvable Mars Campaign," IEEE Aerospace Conference, Big Sky, MT, March 5-12, 2016.

[7] Cassell, A., Brivkalns, C., Garcia, J., Bowles, J., Kinney, D., Yount, B., McGuire, K., Wercinski, P., Cianciolo, A., Polsgrove, T. "Human Mars Mission Design Study Utilizing the Adaptive Deployable Entry and Placement Technology," IEEE Aerospace Conference, Big Sky, MT 2017 (Abstract submitted).

[8] Cerimele, C., Robertson, E., Sostaric, R., Campbell, C., Robinson, P., Hershey, M., Stachowiak, S., Matz, D., Braden, E., Johnson, B., Garcia, J., Bowles, J., Kinney, D. "A Rigid Mid Lift-to-Drag Ratio Approach to Human Mars Entry, Descent, and Landing” AIAA SciTech 2017 Grapevine TX (Abstract submitted).

[9] Price, H., Manning, R., Sklyanskiy, E., Braun, B. “A HighHeritage Blunt-Body Entry Descent, and Landing Concept for Human Mars Exploration” AIAA-2016-0219. 


\section{BIOGRAPHY}

Randolph Lillard ......

Joe Oleniczak ......

Tara Polsgrove ......

Alicia Dwyer Cianciolo

Michelle Munk ......

Charles Whetsel ......

Bret Drake ...... 
